\title{
A Model of Phosphorus Digestion and Metabolism in the Lactating Dairy Cow
}

\author{
S. R. Hill, ${ }^{\star}$ K. F. Knowlton, ${ }^{\star}$ E. Kebreab,† J. France,‡ and M. D. Hanigan* ${ }^{\star 1}$ \\ *Virginia Polytechnic Institute and State University, Blacksburg 24061 \\ †University of Manitoba, Winnipeg, R3T 2N2 Canada \\ $\ddagger$ The University of Guelph, Guelph, N1G 2W1 Canada
}

\section{ABSTRACT}

A dynamic, mechanistic, compartmental model of phosphorus (P) digestion and metabolism was constructed in the Advanced Continuous Simulation Language using conservation of mass principles and mass action kinetics. Phosphorus was assumed to exist in 3 forms: inorganic (Pi), phytic acid $(\mathrm{Pp})$, and organic (excluding phytic acid; Po). All 3 forms were assumed to be present in the digestive tract with absorption of $\mathrm{Pi}$ into blood. Inputs to the model were total P intake; $\mathrm{Pp}, \mathrm{Po}$, and $\mathrm{Pi}$ as proportions of total $\mathrm{P}$; milk yield; rate of salivation (fixed at $239 \mathrm{~L} / \mathrm{d}$ ); and rate of liquid passage from the rumen (fixed at $198 \mathrm{~L} / \mathrm{d}$ ). The model was fitted to 2 experiments from the literature. Derived parameters were well defined by the data. With a mean observed $\mathrm{P}$ intake of $75 \mathrm{~g} / \mathrm{d}$, total tract $\mathrm{P}$ digestibility was $38 \%$. Phytic acid P digestibility in the rumen was $74 \%$, with no additional $\mathrm{Pp}$ digestion in the lower tract. Inorganic $\mathrm{P}$ and $\mathrm{Po}$ digestibility in the lower tract were 48 and $89 \%$, respectively. Flows of $\mathrm{Po}$ and $\mathrm{Pi}$ from the rumen were 2.4 and 3.0 times greater than intake, respectively. The increase in Po was apparently due to microbial growth. The increase in Pi arose primarily from secretion of $\mathrm{Pi}$ into the rumen via salivation where $65 \%$ of absorbed $\mathrm{P}$ was recycled to the rumen. Milk synthesis used $30 \%$ of absorbed $\mathrm{Pi}$, and $1 \%$ was excreted in urine. This research suggested that the primary regulation points for maintaining blood $\mathrm{P}$ were bone deposition and resorption and absorption from the intestine. However, because bone $\mathrm{P}$ balance was related to both dietary $\mathrm{P}$ intake and ruminal phytase activity, it is critical to achieve a better understanding of phytate digestibility across several feeds if dietary $\mathrm{P}$ is to be reduced below current requirements.

Key words: model, phosphorus, dairy cow, digestion and absorption

Received September 4, 2007.

Accepted January 20, 2008.

${ }^{1}$ Corresponding author: mhanigan@vt.edu

\section{INTRODUCTION}

Phosphorus $(\mathrm{P})$ is used in several body processes including critical energy pathways (ATP), cell signaling, and synthesis of cell membranes, RNA, DNA, and bone. Because $\mathrm{P}$ cannot be synthesized, these needs must be met from dietary sources. Because dietary $\mathrm{P}$ cannot be used with perfect efficiency, a portion of dietary $\mathrm{P}$ is excreted, where it is subject to runoff and entry into surface waters (Wu et al., 2003). Contamination of surface waters with $\mathrm{P}$ runoff from livestock farms is a growing concern leading to efforts to devise feeding strategies to maximize $\mathrm{P}$ efficiency of the animal and thus reduce potential runoff (Vandehaar and StPierre, 2006).

In most plant and grain feeds, $\mathrm{P}$ is found bound in the organic form, mainly as phytate or myo-inositol hexakisphosphate (IP-6). However, phytate $\mathrm{P}$ is very poorly digested in the small intestine and thus, is mostly unavailable to monogastric species unless exogenous phytase is added to the feed. The ruminal microbial population synthesizes phytase, which allows digestion of phytate in ruminant species (Liao et al., 2005). Phytase catalyzes the release of phosphate groups from phytic acid. Lower inositols (IP-5, IP-4, and IP-3) are also produced from this reaction and can be further digested and absorbed from the small intestine (Sandberg et al., 1987; Sakamoto et al., 1993). A study by Knowlton et al. (2007) showed improved P digestibility when a mix of phytase and cellulose was fed to lactating cows, indicating that exogenous phytase may be beneficial for improving $\mathrm{P}$ efficiency in the cow and reducing $\mathrm{P}$ excretion.

Much work has been done to decrease the amount of $\mathrm{P}$ fed to dairy cattle and to improve efficiency of $\mathrm{P}$ utilization (Morse et al., 1992; Wu and Satter, 2000; Dou et al., 2003). However, a better quantitative understanding of the extent of phytate (Pp) and nonphytate organic phosphorus (Po) digestion in the rumen and small intestine, regulation of inorganic $\mathrm{P}(\mathbf{P i})$ absorption, secretion of Pi back into the rumen, and excretion of $\mathrm{Pi}$ in urine are required to ensure that $\mathrm{P}$ requirements are met as $\mathrm{P}$ intake is reduced (Vitti et al., 2000). 
Several models have been created to examine changes in P metabolism with dietary changes (Vitti et al., 2000; Bravo et al., 2003; Dias et al., 2006). However, these models have been created to interpret in vivo tracer kinetic data from small ruminants. Those models fractionated $\mathrm{P}$ into 2 pools, phytate and nonphytate. Because it is likely that the digestibility of $\mathrm{Pi}, \mathrm{Po}$, and Pp differ, construction of a model based on these fractions may provide a clearer picture of $\mathrm{P}$ digestion and metabolism. Our objectives were to construct and parameterize a model of $\mathrm{P}$ digestion and metabolism in the lactating cow and use it to identify limiting factors of digestion, absorption, and excretion of $\mathrm{P}$.

\section{MATERIALS AND METHODS}

\section{Overview}

The model consisted of a dynamic system of differential equations, coded in Advanced Continuous Simulation Language (ACSL, Aegis Technology Group, Austin, TX) and contained 5 state variables and 4 compartments. The overall scheme is represented in Figure 1 (flux values represent those derived from the parameterization work described below). Equations were of the mass action form, and units for mass, flux, volume, concentration, and time were grams, grams/day, liters, grams/liter, and days, respectively, unless specified otherwise. Gear's variable step integration algorithm with a maximum step size of $0.005 \mathrm{~d}$ was used for numerical integration.

Abbreviations used throughout were of the following form: $\mathbf{X}_{\mathbf{A}, \mathbf{B}}$, where $\mathbf{X}$ represented $\boldsymbol{C}$ (concentration), $\boldsymbol{F}$ (flux), $\boldsymbol{K}$ (rate constant), $\boldsymbol{P}$ (proportion), or $\boldsymbol{Q}$ (mass or quantity); A was a substrate or pool; and $\mathbf{B}$ a product (Table 1). Where A or B could exist in multiple compartments, the compartment was denoted immediately following the pool; for example, $P p R u m, P p S I, P p L I, P i B l d$ (for rumen, small intestine, large intestine, and blood, respectively).

For model development purposes, a reference state was defined as a cow weighing $600 \mathrm{~kg}$, with a blood volume of $34.2 \mathrm{~L}$ (57 mL/kg of BW; Swenson, 1993), producing $21.9 \mathrm{~kg}$ of milk/d, consuming $23 \mathrm{~kg}$ of DM/d with $0.45 \% \mathrm{P}$, having a ruminal outflow rate of $198 \mathrm{~L} /$ $\mathrm{d}(9.2 \% / \mathrm{h})$ and a salivation rate of $239 \mathrm{~L} / \mathrm{d}$ (Cassida and Stokes, 1986). Dietary P was assumed to be $33.2 \% \mathrm{Pp}$, 44.5\% Pi, and 22.3\% Po (Yang, 2006). However, the model was coded to allow simulation of cattle of varying size and milk production given the appropriate inputs as demonstrated by use of 2 data sets for parameter estimation as described below. The model may be adapted for young growing animals and mature nonlactating animals with appropriate changes in rate constants for deposition of $\mathrm{P}$ in bone, tissues, and milk.

\section{Model Derivation}

Three fractions of $\mathrm{P}$ were considered; $\mathrm{Pp}, \mathrm{Po}$, and $\mathrm{Pi}$. Organic $\mathrm{P}$ was characterized as $\mathrm{P}$ bound to a carbon molecule exclusive of phytate, and Pi was characterized as unbound or elemental $P$. The third fraction, phytate $\mathrm{P}$ or phytic acid, is generally considered part of $\mathrm{Po}$. However, in this model, the Pp pool was considered separately because the digestibility of $\mathrm{Pp}$ in the small intestine is low and Pp can be degraded in the rumen via microbial action. These 3 forms of $\mathrm{P}$ were represented in the rumen (Rum), the small intestine (SI), and the large intestine (LI). Additionally, $\mathrm{Pi}$ in blood and bone was represented. A description of each compartment follows.

\section{The Rumen}

The differential equation describing ruminal $\mathrm{Pp}$ $\left(\mathrm{d} Q_{P p R u m} / d t\right)$ was represented as the balance of input from feed $\left(F_{P p F d, P p R u m}\right)$, degradation $\left(F_{P p, \text { DegRum }}\right)$, and flow to the small intestine $\left(F_{P p R u m, P p S I}\right)$ :

$$
\begin{aligned}
\frac{\mathrm{d} Q_{P p R u m}}{\mathrm{~d} t}= & F_{P p F d, P p R u m}-F_{P p, \text { DegRum }} \\
& -F_{P p R u m, P p S I},
\end{aligned}
$$

Dietary input of phytic acid to the rumen was calculated from the input of total dietary $\mathrm{P}\left(F_{P t F d}\right)$ based on the DMI $(\mathrm{kg} / \mathrm{d})$, the proportion of $\mathrm{P}$ in the $\operatorname{diet}\left(P_{P t F d}\right.$, $\mathrm{g} / \mathrm{g}$ of DM), and the proportion of $\mathrm{Pp}$ in dietary $\mathrm{P}\left(P_{P p P t}\right.$, $\mathrm{g} / \mathrm{g})$ :

$$
\begin{gathered}
F_{P t F d}=D M I \times P_{P t F d} ; \\
F_{P p F d, P p R u m}=F_{P t F d} \times P_{\mathrm{PpPt} .}
\end{gathered}
$$

The initial step of Pp digestion releases 1 molecule of $\mathrm{Pi}$, leaving organic pentaphosphate (IP-5, a member of Po). Thus, degradation of $6 \mathrm{~g}$ of Pp was assumed to result in $1 \mathrm{~g}$ of $\mathrm{Pi}$ and $5 \mathrm{~g}$ of Po. Overall degradation of Pp in the rumen $\left(F_{P p R u m, \text { DegRum }}\right)$ and entry of Pp into the Po $\left(F_{\text {PpRum,PoRum }}\right)$ and $\mathrm{Pi}\left(F_{P p R u m, P i R u m}\right)$ pools of the rumen were calculated as

$$
\begin{gathered}
F_{\text {PpRum }, \text { DegRum }}=Q_{P p R u m} \times K_{P p R u m, \text { DegRum }} ; \\
F_{P p R u m, \text { PiRum }}=F_{P p R u m, \text { DegRum }} \times \frac{1}{6} ; \\
F_{P p \text { Rum }, \text { PoRum }}=F_{P p \text { Rum }, \text { DegRum }}-F_{P p R u m, \text { PiRum }} .
\end{gathered}
$$

Phytate is also subject to escape from the rumen $\left(F_{P p R u m, P p S I}\right)$ via ruminal outflow through the reticuloomasal orifice: 


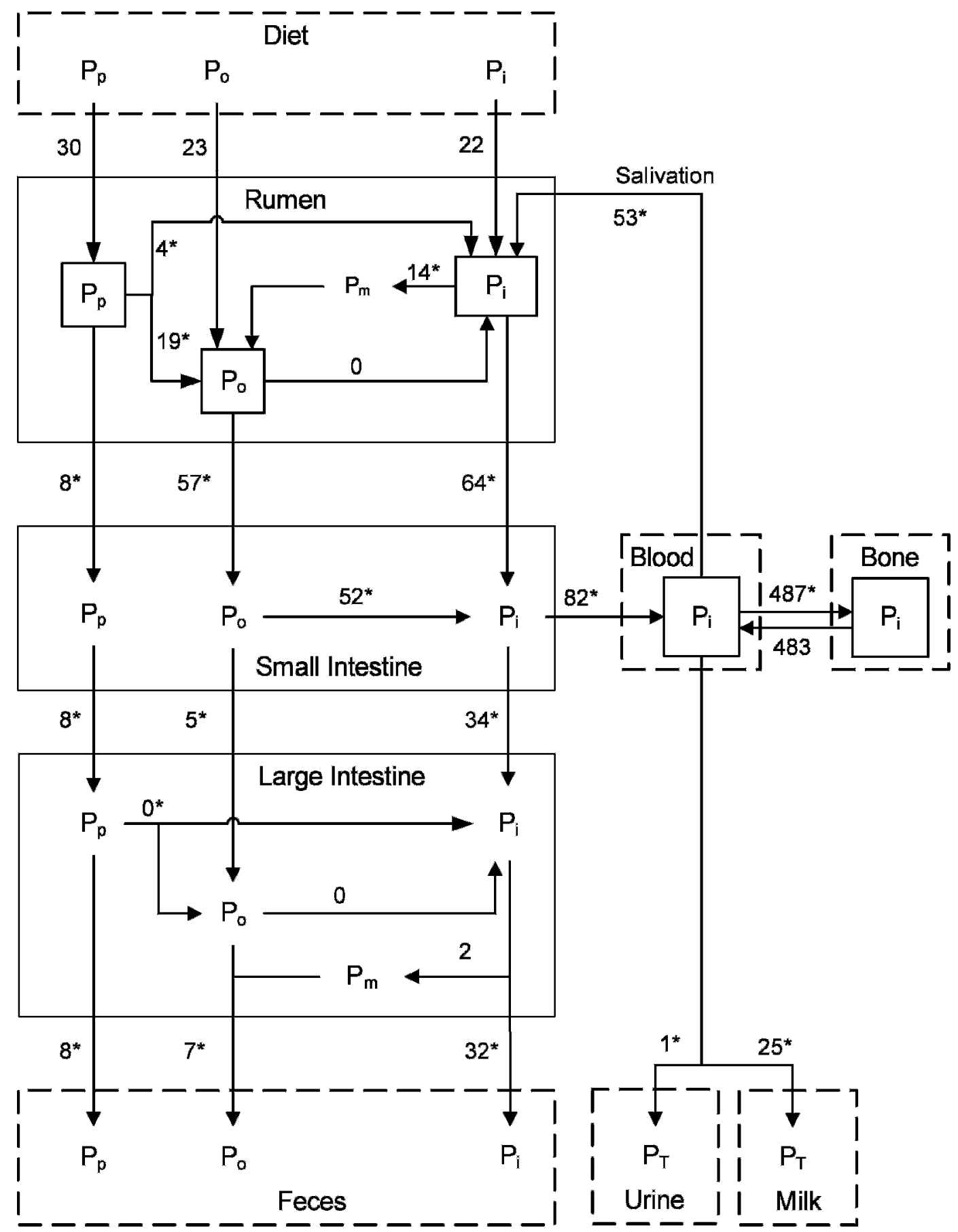

Figure 1. Schematic representation of phosphorus (P) absorption and metabolism in a lactating cow. Boxes with solid lines represent pools, boxes with dashed lines represent compartments, and solid arrows represent fluxes. Numbers associated with arrows are the predicted fluxes $(\mathrm{g} / \mathrm{d})$ from the data of Schwab et al. (2006) and Knowlton et al. (2001). An asterisk (*) indicates the flux was derived from the data; fluxes not denoted with an asterisk were assumed. $\mathrm{P}_{\mathrm{T}}=$ total $\mathrm{P} ; \mathrm{P}_{\mathrm{p}}=$ phytate $\mathrm{P} ; \mathrm{P}_{\mathrm{o}}=$ organic $\mathrm{P}$ excluding phytate; $\mathrm{P}_{\mathrm{i}}=$ inorganic $\mathrm{P} ; \mathrm{P}_{\mathrm{m}}=$ microbial P.

$$
F_{P p R u m, P p S I}=C_{P p R u m} \times F_{\text {LiqRum,LiqSI }},
$$

where $F_{\text {LiqRum,LiqSI }}$ represented the fluid flow from the rumen, which was assumed to be $198 \mathrm{~L} / \mathrm{d}$.

$Q_{P p R u m}$ represented the mass of $\mathrm{P}$ in the form of phytic acid in the rumen at any time $t$ and was determined by numerical integration of equation [1] from a given initial mass $\left(i Q_{P p R u m}\right)$, which was estimated to be $9.0 \mathrm{~g}$ 
Table 1. Symbols used in the model

\begin{tabular}{ll}
\hline Symbol & Definition \\
\hline Bld & Blood \\
Bone & Bone \\
$C_{a}$ & Concentration of $a$ \\
Deg & Degradation of $\mathrm{P}$ \\
$F_{a, b}$ & Flux from pool $a$ to pool $b$ \\
$F d$ & Feed \\
$F e$ & Feces \\
$i X_{a}$ & Initial concentration $(\mathrm{C})$ or mass $(\mathrm{Q})$ of $a$ \\
$K_{a, b}$ & Rate constant associated with the flux from pool $a$ \\
$L I$ & to pool $b$ \\
$L i q$ & Large intestine \\
$M l k$ & Fluid \\
$P_{a b}$ & Milk \\
$P_{i}$ & Proportion of $a$ in $b$ \\
$P_{m}$ & Inorganic $\mathrm{P}$ \\
$P_{o}$ & Microbial P \\
$P_{p}$ & Organic P excluding phytate P \\
$P_{T}$ & Phytate P \\
$Q_{a}$ & Total P \\
$R u m$ & Quantity or mass of $a$ \\
$S a l$ & Rumen \\
$S I$ & Saliva \\
Urn & Small intestine \\
\hline
\end{tabular}

based on the work of Yang (2006). The concentration of Pp in the rumen $\left(C_{P p R u m}\right)$ at any $t$ was calculated from the volume $\left(V_{\text {Rum }}, \mathrm{L}\right)$ of the ruminal compartment as:

$$
C_{\text {PpRum }}=\frac{Q_{P p R u m}}{V_{\text {Rum }}},
$$

where $V_{\text {Rum }}$ was assumed to be $90 \mathrm{~L}$.

Organic P was assumed to represent IP-5, IP-4, IP3 , phospholipids, and microbial-bound $\mathrm{P}(\mathrm{Pm})$. The differential equation describing $\mathrm{Po}$ in the rumen was represented as the balance between inputs from feed $\left(F_{\text {PoFd,PoRum }}\right)$, conversion of Pp to Po $\left(F_{P p R u m, P o R u m}\right), \mathrm{Pi}$ converted to $\mathrm{Po}$ in association with microbial growth $\left(F_{\text {PiRum,PmRum }}\right)$, degradation of $\mathrm{Po}_{(}\left(\boldsymbol{F}_{\text {PoRum,PiRum }}\right)$ and flux to the small intestine $\left(F_{\text {PoRum,PoSI }}\right)$ :

$$
\begin{gathered}
\frac{\mathrm{d} Q_{\text {PoRum }}}{\mathrm{d} t}=F_{\text {PoFd,PoRum }}+F_{\text {PpRum,PoRum }} \\
+F_{\text {PiRum,PmRum }}-F_{\text {PoRum,PiRum }}-F_{\text {PoRum,PoSI }} .
\end{gathered}
$$

$F_{\text {PoFd,PoRum }}$ was calculated in the same manner as for $\mathrm{Pp}$ in equation [3]:

$$
F_{P o F d, P o R u m}=F_{P t F d} \times P_{P o P t} .
$$

Conversion of Po to $\mathrm{Pi}$ in the rumen $\left(F_{\text {PoRum,PiRum }}\right)$ represented degradation via phosphatase and was calculated as

$$
F_{\text {PoRum,PiRum }}=Q_{\text {PoRum }} \times K_{\text {PoRum, PiRum }} .
$$

Flow of Po from the rumen to the small intestine $\left(F_{\text {PoRum,PoSI }}\right)$ was calculated in the same manner as for $\mathrm{Pp}$ in equation [6]:

$$
F_{\text {PoRum,PoSI }}=C_{\text {PoRum }} \times F_{\text {LiqRum,LiqSI }} .
$$

The lower inositols (IP-5, IP-4, IP-3) could then be digested further to produce more $\mathrm{Pi}$ or flow from the rumen to small intestine.

$Q_{\text {PoRum }}$ represented the mass of organic P in the rumen at any time $t$ and was determined by numerical integration of equation [9] from a given initial mass ( $\left.i Q_{\text {PoRum }}\right)$, which was assumed to be $10.8 \mathrm{~g}$ based on the observations of Yang (2006). The concentration of Po in the rumen at any $t$ was calculated as

$$
C_{\text {PoRum }}=\frac{Q_{\text {PoRum }}}{V_{\text {Rum }}} .
$$

Inorganic $\mathrm{P}$ flow in the rumen was represented by the balance between inputs from feed $\left(F_{P i F d, P i R u m}\right)$ conversion of $\mathrm{Po}\left(F_{\text {PoRum,PiRum }}\right)$ and $\mathrm{Pp}\left(F_{P p \text { Rum,PiRum }}\right)$ to $\mathrm{Pi}$, recycling of salivary $\mathrm{P}\left(F_{P i B l d, P i R u m}\right)$, utilization by the microbial population $\left(F_{\text {PiRum,PmRum }}\right)$, and flow to the small intestine $\left(F_{\text {PiRum,PiSI }}\right)$ :

$$
\begin{gathered}
\frac{\mathrm{d} Q_{\text {PiRum }}}{\mathrm{d} t}=F_{\text {PiFd,PiRum }}+F_{\text {PoRum,PiRum }} \\
+F_{\text {PpRum,PiRum }}+F_{\text {PiBld,PiRum }}-F_{\text {PiRum,PmRum }} \\
-F_{\text {PiRum,PiSI. }} .
\end{gathered}
$$

$F_{P i F d, P i R u m}$ was calculated as for Pp:

$$
F_{P i F d, P i R u m}=F_{P t F d} \times P_{P i P t} .
$$

According to Kebreab and Vitti (2005), 45\% of the total rumen $\mathrm{P}$ is recycled in saliva and many studies have shown that salivary $\mathrm{P}$ is in the inorganic form (Tomas, 1973; Scott and Buchan, 1987; Bravo et al., 2003). Although salivary secretion rate is affected by diet, concentration of $\mathrm{Pi}$ in saliva appears to remain constant (Tomas, 1973). Therefore, the flux of Pi into the rumen due to recycling in saliva $\left(F_{\text {PiBld,PiRum }}\right)$ was assumed to be a function of salivary rate $\left(F_{S a l}\right)$ and $\mathrm{Pi}$ concentrations in blood:

$$
F_{P i B l d, P i R u m}=F_{S a l} \times K_{P i B l d, P i R u m} \times C_{P i B l d} .
$$

Inorganic $\mathrm{P}$ in the rumen is also utilized by the microbial population and this relationship was considered in the model. A deficiency of $\mathrm{Pi}$ in the rumen can lead to impaired rumen fermentation. Komisarczuk et al. (1987) found that with ruminal total $\mathrm{P}$ concentration 
less than $0.1 \mathrm{~m} M$, cellulose digestion and VFA production decreased, as did protein synthesis at $0.03 \mathrm{mM}$ ruminal total $\mathrm{P}(\mathbf{P t})$. These ruminal $\mathrm{Pt}$ concentrations are much lower than concentrations found in P-depleted sheep (Breves and Holler, 1987), in which no ill effects were seen. Although $\mathrm{P}$ deficiency sufficient to cause depressed microbial activity may be rare, $\mathrm{P}$ is clearly required for microbial growth. In the model, this is represented as

$$
F_{\text {PiRum }, \text { PmRum }}=Q_{\text {PiRum }} \times K_{\text {PiRum }, \text { PmRum }},
$$

where $K_{\text {PiRum,PmRum }}$ represents microbial $\mathrm{P}$ growth rates. Ideally, $K_{\text {PiRum,PmRum }}$ would be replaced with a variable representation of microbial growth as microbial needs for $\mathrm{P}$ are presumably driven by growth rates rather than the static conversion rate herein. However, such a complex representation is beyond the scope of this work.

Flow of $\mathrm{Pi}$ from the rumen to the small intestine $\left(F_{P i R u m, P i S I}\right)$ was calculated in the same manner as for Pp:

$$
F_{P i R u m, P i S I}=C_{P i R u m} \times F_{\text {LiqRum,LiqSI }} .
$$

$Q_{P i R u m}$ represented the mass of inorganic $\mathrm{P}$ in the rumen at any time $t$ and was determined by numerical integration of equation [15] from a given initial mass $\left(i Q_{\text {PiRum }}\right)$, which was estimated to be $16.2 \mathrm{~g}$ based on the observations of Witt and Owens (1983). The concentration of $P o$ in the rumen at any $t$ was calculated as:

$$
C_{\text {PiRum }}=\frac{Q_{\text {PiRum }}}{V_{\text {Rum }}} .
$$

\section{The Lower Tract}

Because $\mathrm{P}$ flow through the lower gastrointestinal tract is largely dependent on outflow from the rumen and the lower gastrointestinal tract does not represent a homogeneous mixed pool, the LI and SI pools were treated as zero-sum pools as described previously by France et al. (1992). This was accomplished by a series of algebraic equations with fractional rate constants describing conversion from one pool to the next with the sum of inputs set equal to the sum of outputs.

Absorption and flow of $\mathrm{P}$ from the small intestine was defined as

$$
\begin{gathered}
F_{P o S I, P i S I}=F_{P o R u m, P o S I} \times K_{P o S I, P i S I} ; \\
F_{P i S I, P i B l d}=\left(F_{P i R u m, P i S I}+F_{P o S I, P i S I}\right) \times K_{P i S I, P i B l d} \\
\times\left(i Q_{P i B l d} / Q_{P i B l d}\right)^{x_{P i S I}, P i B l d} ;
\end{gathered}
$$

$$
\begin{gathered}
F_{P p S I, P p L I}=F_{P p R u m, P p S I} ; \\
F_{P o S I, P o L I}=F_{P o R u m, P o S I}-F_{P o S I, P i S I} ; \text { and } \\
F_{P i S I, P i L I}=F_{P i R u m, P i S I}+F_{P o S I, P i S I}-F_{P i S I, P i B l d} .
\end{gathered}
$$

Absorption of Pi from the small intestine is a saturable process probably best described by Michaelis-Menten kinetics, but in the absence of data to define the equation, mass action kinetics were used. Blood Pi was included as a feedback inhibitor of absorptions to reflect the impact of postabsorptive demand on $\mathrm{P}$ absorption as previously observed (Hibbs and Conrad, 1983). An exponent $\left(x_{P i S I, P i B l d}\right)$ was included in equation [21] to allow the magnitude of the effect of blood $\mathrm{P}$ on absorption to be derived including complete removal of the effect if the exponent is set to 0 . The exponent was set to 1 .

Absorption and flow from the large intestine was defined by the following equations:

$$
\begin{gathered}
F_{P p L I, D e g L I}=F_{P p S I, P p L I} \times K_{P p L I, D e g L I} ; \\
F_{P p L I, P i L I}=F_{P p L I, D e g L I} \times \frac{1}{6} ; \\
F_{P p L I, P o L I}=F_{P p L I, D e g L I}-F_{P p L I, P i L I} ; \\
F_{P o L I, P i L I}=F_{P o S I, P o L I} \times K_{P o L I, P i L I} ; \text { and } \\
F_{P i L I, P m L I}=F_{P i S I, P i L I} \times K_{P i L I, P m L I}
\end{gathered}
$$

Fecal output was calculated as

$$
\begin{gathered}
F_{P p L I, P p F e}=F_{P p S I, P p L I}-F_{P p, D e g L I} ; \\
F_{P o L I, P o F e}=F_{P o S I, P o L I}+F_{P p L I, P o L I}+F_{P i L I, P m L I} \\
-F_{P o L I, P i L I} ; \text { and } \\
F_{P i L I, P i F e}=F_{P i S I, P i L I}+F_{P o L I, P i L I}+F_{P p L I, P i L I} \\
-F_{P i L I, P m L I} .
\end{gathered}
$$

\section{Blood Phosphorus}

Concentrations of $\mathrm{Pi}$ in blood are relatively constant (Bravo et al., 2003). The differential equation representing $\mathrm{Pi}$ in blood was defined as

$$
\begin{gathered}
\frac{\mathrm{d} Q_{P i B l d}}{\mathrm{~d} t}=F_{P i B o n e, P i B l d}+F_{P i S l, P i B l d}-F_{P i B l d, P i B o n e} \\
-F_{P i B l d, P i M l k}-F_{P i B l d, P i R u m}-F_{P i B l d, P i U r n} .
\end{gathered}
$$


Inorganic $\mathrm{P}$ absorbed from the small intestine $\left(F_{P i S i,-}\right.$ $P i B l d)$ and released from bone $\left(F_{P i B o n e, P i B l d}\right)$ were inputs to blood. The primary routes of removal of Pi from blood were recycling to the rumen via saliva $\left(F_{P i B l d, P i R u m}\right)$ and deposition in bone $\left(F_{\text {PiBld,PiBone }}\right)$. Phosphorus was secreted into milk $\left(F_{P i B l d, P i M l k}\right)$ and a minimal amount of $\mathrm{Pi}$ was excreted in urine $\left(F_{P i B l d, P i U r n}\right)$. Flux of Pi from blood to urine was a function of blood concentrations of Pi. Equations representing removal of Pi from blood to urine and milk were

$$
\begin{gathered}
F_{P i B l d, P i U r n}=\left(Q_{P i B l d} / i Q_{P i B l d}\right)^{x} P i B l d \\
\times K_{P i B l d, P i U r n} \text { and } \\
F_{P i B l d, P i M l k}=F_{M l k} \times K_{P i B l d, P i M l k},
\end{gathered}
$$

where $Q_{P i B l d}$ was derived by numerical integration from an initial mass $\left(i Q_{P i B l d}\right)$ of $8.5 \mathrm{~g}$ (Knowlton et al., 2001). The concentration of $\mathrm{Pi}$ in milk was assumed to be constant; thus, the flux was dependent on the rate of milk $\left(F_{M l k}\right)$ secretion. The salivary flux was described previously (equation [16]).

\section{Bone Phosphorus}

The differential equation for $\mathrm{P}$ in bone was represented as

$$
\frac{\mathrm{d} Q_{\text {PiBone }}}{\mathrm{d} t}=F_{\text {PiBld,PiBone }}-F_{\text {PiBone,PiBld }} \text {. }
$$

Mobilization of bone $\left(F_{\text {PiBone,PiBld }}\right)$ due to lactation demands is controlled by several factors including parathyroid hormone and blood $\mathrm{Ca}$ and $\mathrm{P}$ (Horst, 1986). Of those factors, blood $\mathrm{P}$ was explicitly represented, whereas the others were not due to lack of data; the model structure would allow their incorporation as quantitative data become available. Mobilization and deposition $\left(F_{\text {PiBld,PiBone }}\right)$ were represented as

$$
\begin{gathered}
F_{\text {PiBld,PiBone }}=Q_{P i B l d} \times F_{P i B l d, \text { PiBone }} \text { and } \\
F_{\text {PiBone,PiBld }}=Q_{\text {PiBone }} \times K_{\text {PiBone,PiBld }},
\end{gathered}
$$

where $Q_{P i B o n e}$ was derived by numerical integration from an initial mass $\left(i Q_{P i B o n e}\right)$ of 4,800 $\mathrm{g}$ (Georgievskii et al., 1982). Based on the P flux observations of Dias et al. (2006), release of $\mathrm{P}$ from bone was set at $10 \% / \mathrm{d}$; that is, $K_{\text {PiBone,PiBld }}$ was set to 0.1 .

\section{Parameter Estimation and Model Evaluation}

Parameter estimation was conducted using ACSL Math/Optimize (V2.5.4, Aegis Technologies Group).
Data for parameter estimation were derived from feed, duodenal, and fecal samples provided by Schwab et al. (2006; P intake, duodenal P flow and fractionation, and fecal $P$ flow and fractionation) and the observations of Knowlton et al. (2001; P intake and fecal output, milk $\mathrm{P}$ output, and blood $\mathrm{P}$ concentrations). Total $\mathrm{P}$ was determined by colorimetric analysis and $\mathrm{P}$ fractionation of the duodenal and fecal samples was by nuclear magnetic resonance spectroscopy (Yang, 2006).

Model inputs used were feed intake; $\mathrm{P}$ content of the feed; the proportions of $\mathrm{Pp}, \mathrm{Po}$, and $\mathrm{Pi}$ in feed $\mathrm{Pt}$; and milk yield (Table 2). Feed intake, dietary total $\mathrm{P}$ content, and milk yields were measured. The proportions of $\mathrm{Pp}, \mathrm{Po}$, and $\mathrm{Pi}$ in feed $\mathrm{P}$ were derived using tabular information from the literature (Clark et al., 1986; Eeckhout and Paepe, 1994; Godoy et al., 2005). The model was fitted against duodenal flows of $\mathrm{Pp}, \mathrm{Po}, \mathrm{Pi}$, and Pt; fecal flows of Pp, Po, Pi, and Pt; blood Pi concentration; excretion of $\mathrm{Pi}$ in milk and urine while varying the parameters listed in Table 3. The objective function was a log-likelihood function that was calculated from unweighted residual errors and maximized using generalized-reduced gradient or Nelder-Mead optimization algorithms. Solutions were checked from different starting points and with both algorithms in an attempt to ensure the solutions were global. All reported results are derived from the generalized reduced gradient solutions.

Initial parameter estimates for phytate degradation in the LI $\left(K_{P p L I, D e g L I}\right)$ were found to be $-0.16 \pm 0.18$, indicating that no phytate degradation occurred after material left the rumen, and thus $K_{P p L I, D e g L I}$ was set to zero for all subsequent parameter estimation work.

In the absence of tracers, the cycling of $\mathrm{Po}$ to $\mathrm{Pi}$ and $\mathrm{Pi}$ to $\mathrm{Pm}$ in the rumen and hindgut cannot be uniquely determined. Microbial flow from the rumen averaged $334 \mathrm{~g} / \mathrm{d}$ for the Schwab et al. (2006) experiment. The P content of ruminal microbes has been found to be variable averaging $3.5 \%$ on a DM basis (Durand and Kawashima, 1980), yielding an expected synthesis rate of Pm of $12 \mathrm{~g} / \mathrm{d}$. Because Po flow at the SI was observed to be $14 \mathrm{~g} / \mathrm{d}$ greater than Po input from feed, the expected synthesis of Po by microbes (Pm) accounts for all the apparent increase leaving no additional Po for degradation in the rumen; that is, any degradation of Po would necessitate additional microbial synthesis from $\mathrm{Pi}$ to maintain ruminal Po balance. Based on these observations, $K_{\text {PoRum,PiRum }}$ was set to zero; however, if the $\mathrm{P}$ content of microbes were greater than $3.5 \%$, then some degradation of $\mathrm{Po}$ and resynthesis by microbes would be consistent with the balance observations. The same assumption regarding Po degradation was made for the LI. 
Table 2. Model inputs for the studies of Schwab et al. (2006) and Knowlton et al. (2001)

\begin{tabular}{|c|c|c|c|c|c|c|c|c|}
\hline \multirow[b]{2}{*}{ Input $^{1}$} & \multicolumn{4}{|c|}{ Schwab $^{2}$} & \multicolumn{4}{|c|}{ Knowlton $^{3}$} \\
\hline & $35-30$ & $35-40$ & $60-30$ & $60-40$ & SBM-Min & SBM-WB & BM-Min & BM-WB \\
\hline Milk yield, kg/d & 32.7 & 35.1 & 29.3 & 32.1 & 36.3 & 33.3 & 33.8 & 32.4 \\
\hline DMI, $\mathrm{kg} / \mathrm{d}$ & 21.3 & 22.2 & 18.1 & 19.8 & 23.5 & 20.9 & 22.5 & 20.6 \\
\hline $\mathrm{P}_{\mathrm{PtFd}}$ & 0.0035 & 0.0036 & 0.0036 & 0.0036 & 0.0038 & 0.0034 & 0.0036 & 0.0034 \\
\hline $\mathrm{P}_{\mathrm{PpPt}}$ & 0.31 & 0.41 & 0.19 & 0.30 & 0.41 & 0.61 & 0.40 & 0.58 \\
\hline $\mathrm{P}_{\mathrm{PoPt}}$ & 0.22 & 0.19 & 0.16 & 0.17 & 0.51 & 0.33 & 0.51 & 0.36 \\
\hline $\mathrm{P}_{\mathrm{PiPt}}$ & 0.47 & 0.40 & 0.64 & 0.54 & 0.09 & 0.06 & 0.09 & 0.06 \\
\hline
\end{tabular}

${ }^{1} \mathrm{P}_{\mathrm{PtFd}}=$ proportion of total $\mathrm{P}$ in feed, $\mathrm{g} / \mathrm{g}$ of $\mathrm{DM} ; \mathrm{P}_{\mathrm{PpPt}}=$ proportion of total feed $\mathrm{P}$ as phytate $\mathrm{P}, \mathrm{g} / \mathrm{g} ; \mathrm{P}_{\mathrm{PoPt}}=$ proportion of total feed $\mathrm{P}$ as nonphytate organic $\mathrm{P}, \mathrm{g} / \mathrm{g} ; \mathrm{P}_{\mathrm{PiPt}}=$ proportion of total feed $\mathrm{P}$ as inorganic $\mathrm{P}$, $\mathrm{g} / \mathrm{g}$.

${ }^{2}$ Treatments designate the percentage of forage (first value) and NFC (second value) in the diet.

${ }^{3}$ Treatments denote soybean meal (SBM) or blood meal (BM) used as a protein source and inorganic minerals (Min) or wheat bran (WB) as a source of phosphorus in the diets.

Organic matter digestion in the LI represents approximately $15 \%$ of that in the rumen when animals are fed typical dairy rations (Callison et al., 2001). As microbial growth is driven by organic matter digestion, microbial growth in the LI could be expected to be $15 \%$ of those in the rumen. Based on that assumption and assuming microbial $\mathrm{P}$ content is the same in the LI as for the rumen, $P$ m synthesis was estimated to be $1.8 \mathrm{~g} / \mathrm{d}$ in the current work, and $K_{P i L I, P m L I}$ was set to 0.05 to achieve that rate.

Root mean square prediction errors (RMSPE) and a decomposition of those errors were calculated as described previously (Bibby and Toutenberg, 1977). Sensitivity coefficients were conducted using acslXtreme (V2.4.0.11, Aegis Technologies Group). The sensitivity coefficient was calculated as

$$
\text { Sensitivity coefficient }=\frac{f(x+\Delta x)-f(x)}{\Delta x} \text {, }
$$

where $f(x)$ represents the model prediction for an output variable (the predicted value) at a specified value for $x$ and $f(x+\Delta x)$ represents the model prediction at $x+$ $\Delta x$, where $\Delta x$ was 0.0001 . A forward difference method was used ( $\Delta x$ was only tested in the positive direction) and the model was configured to run an 11-d simulation.

\section{RESULTS AND DISCUSSION}

The model was found to be stable when using a maximum step size of $0.005 \mathrm{~d}$ as evidenced by the ability to achieve steady state under reference conditions and return to that same state following a perturbation of dietary $\mathrm{P}$ inputs and the lack of inappropriate oscillations in any pools (data not shown).

Parameter estimates derived from fitting the model to the observed data with $x_{P i S I, P i B l d}$ set to 1 are presented in Table 3. The standard deviations of parameter estimates were low ( $<15 \%$ of the parameter estimate), indi-

Table 3. Parameter estimates and standard deviations derived from fitting to the data of Schwab et al. (2006) and Knowlton et al. (2001) with differing assumptions regarding nonphytate organic $\mathrm{P}(\mathrm{Po})$ degradation and microbial synthesis of Po in the large intestine

\begin{tabular}{lccccc}
\hline Parameter $^{1}$ & Estimate $^{2}$ & SD & Estimate $^{3}$ & Estimate $^{4}$ & Estimate $^{5}$ \\
\hline$K_{\text {PpRum,DegRum }}, \mathrm{d}^{-1}$ & 6.1 & 0.8 & 6.1 & 6.1 & 6.2 \\
$K_{\text {PiRum,PmRum }}, \mathrm{d}^{-1}$ & 0.49 & 0.05 & 0.49 & 0.48 & 0.49 \\
$K_{\text {PoSI,PiSI }}, \mathrm{g} / \mathrm{g}$ & 0.92 & 0.01 & 0.89 & 0.96 & 0.94 \\
$K_{P i S I, P i B l d}, \mathrm{~g} / \mathrm{g}$ & 0.46 & 0.01 & 0.47 & 0.45 & 0.46 \\
$K_{\text {PiBld,PiSal }}, \mathrm{unitless}$ & 0.15 & 0.005 & 0.15 & 0.15 & 0.15 \\
$K_{\text {PiBld,PiUrn }}, \mathrm{g} / \mathrm{d}$ & 1.06 & 0.07 & 1.06 & 1.06 & 1.06 \\
$K_{P i \text { Bld,PiMlk }}, \mathrm{g} / \mathrm{L}$ & 0.74 & 0.01 & 0.74 & 0.74 & 0.74 \\
$K_{\text {PiBld,PiBone }}, \mathrm{d}^{-1}$ & 326 & 5 & 325 & 327 & 327 \\
\hline
\end{tabular}

${ }^{1}$ Parameter abbreviations as given in Table 1.

${ }^{2}$ Po degradation $\left(K_{P o L I, P i L I}\right)$ and microbial synthesis $\left(K_{P i L I, P m L I}\right)$ of Po in the large intestine assumed to be 0 as discussed in Materials and Methods.

${ }^{3} K_{P o L I, P i L I}$ set to 0.25 ; that is, $25 \%$ of Po entry to the large intestine is degraded to inorganic P.

${ }^{4} K_{P i L I, P m L I}$ set to 0.1 ; that is, $10 \%$ of Pi entry to the large intestine is converted to Po via microbial action.

${ }^{5} K_{P o L I, P i L I}$ set to 0.25 and $K_{P i L I, P m L I}$ set to 0.1 . 
Table 4. Model prediction errors (RMSPE) associated with predictions of the data of Schwab et al. (2006) and Knowlton et al. (2001)

\begin{tabular}{|c|c|c|c|c|c|c|}
\hline Variable $^{1}$ & $\begin{array}{l}\text { Mean observed, } \\
\text { g/d }\end{array}$ & $\begin{array}{l}\text { Mean predicted, } \\
\text { g/d }\end{array}$ & $\begin{array}{l}\text { RMSPE, } \\
\text { g/d }\end{array}$ & $\begin{array}{c}\text { RMSPE, } \\
\text { \% of observed }\end{array}$ & $\begin{array}{l}\text { Mean bias, } \\
\% \text { of } \text { MSPE }^{2}\end{array}$ & $\begin{array}{l}\text { Slope bias, } \\
\% \text { of MSPE }\end{array}$ \\
\hline$F_{P p R u m, P p S I}$ & 6 & 6 & 1.9 & 30 & 4 & 95 \\
\hline$F_{\text {PoRum,PoSI }}$ & 44 & 44 & 5.3 & 12 & 2 & 89 \\
\hline$F_{P i R u m, P i S I}$ & 76 & 75 & 4.4 & 6 & 0.2 & 62 \\
\hline$F_{\text {PtRum,PtSI }}$ & 126 & 126 & 5.5 & 4 & 0.1 & 34 \\
\hline$F_{P p L I, P p F E}$ & 7 & 6 & 2.2 & 31 & 36 & 59 \\
\hline$F_{P o L I, P o F E}$ & 5.4 & 5.4 & 0.4 & 8 & 3 & 50 \\
\hline$F_{P i L I, P i F E}$ & 33 & 32 & 1.9 & 6 & 6 & 5 \\
\hline$F_{P t L I, P t F E}$ & 43 & 49 & 6.3 & 15 & 95 & 1 \\
\hline$F_{P i B l d, P i M l k}$ & 25 & 25 & 1.3 & 5 & 0.0004 & 1 \\
\hline$F_{P i B l d, P i U r n}$ & 0.7 & 0.7 & 0.1 & 17 & 0.0004 & 19 \\
\hline$C_{P i B l d}, \mathrm{~g} / \mathrm{L}$ & 0.044 & 0.043 & 0.002 & 4 & 0.01 & 76 \\
\hline
\end{tabular}

${ }^{1}$ Variable abbreviations as given in Table 1.

${ }^{2} \mathrm{MSPE}=$ mean square prediction error.

cating that the data were adequate to define the model given the adopted assumptions. Prediction errors were reasonable for all predicted outputs $(<20 \%$ of the observed value) with the exception of phytate $\mathrm{P}$ flow to the small intestine and excretion in feces (Table 4). For these variables, the RMSPE were 30 and $31 \%$, respectively. Because most of the prediction errors for these 2 variables were associated with slope bias (95 and $59 \%$, respectively), the representation of Pp may be inadequate. Slopes of residual vs. predicted were negative for both, indicating that the model overpredicted flows to a greater extent as predicted flow increased (Figure 2). This may suggest that some adaptive response is present in the rumen allowing greater phytase activity as phytate intake increases. However, this conclusion is based on 4 treatment means and thus additional evaluations are needed to further test this hypothesis.

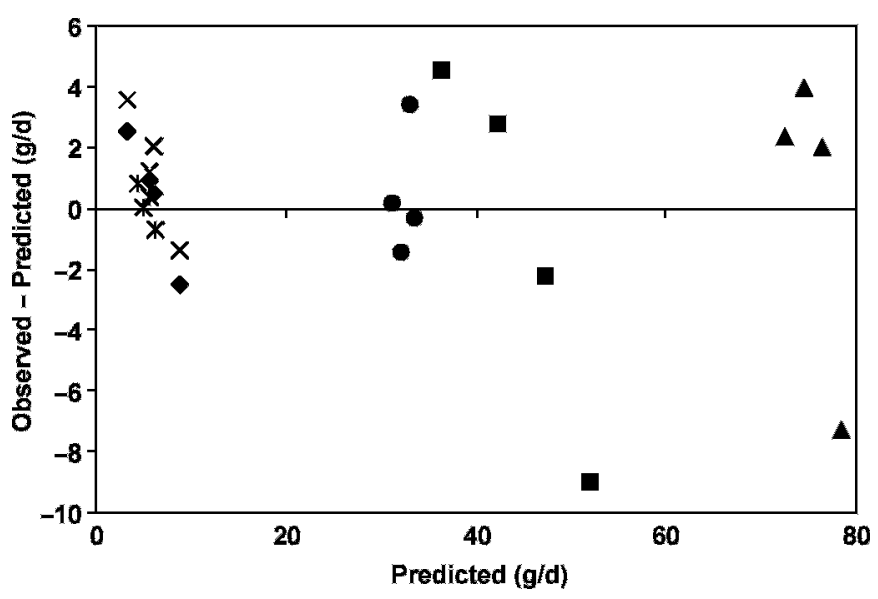

Figure 2. Residual errors for predictions of digesta phosphorus flux: $\bullet=F_{P p R u m, P p S I} ; \mathbf{\square}=F_{P o R u m, P o S I} ; \boldsymbol{\Delta}=F_{P i R u m, P i S I} ; \times=F_{P p L I, P p F e}$; $*=F_{P o S L, P o F e} ; \boldsymbol{O}=F_{P i L I, P i F e}$.
Slope bias was also high for the flux of organic $\left(F_{\text {PoRum,PoSI }} ; 89 \%\right)$ and inorganic $\mathrm{P}$ into the small intestine $\left(F_{\text {PiRum,PiSI }} ; 62 \%\right)$ and organic flow to feces $\left(F_{\text {PoLI,PoFe }} ; 50 \%\right)$; however, the RMSPE for these predictions were relatively low, and thus the magnitude of the slope bias was moderate. Errors in predicting flux of Pi in the feces, Pi in milk, and blood Pi concentrations were all found to be low. Mean bias was relatively high for phytate and total $\mathrm{P}$ flow to feces.

The correlation matrix for parameters is presented in Table 5. Most parameters were not highly correlated. However, correlation coefficients were greater than 0.5 for 2 pairs of parameter estimates: $K_{P O S I, P i S I}$ and $K_{\text {PiRun,PmRum }}$, and $K_{\text {PiSI,PiBld }}$ and $K_{\text {PiBld,PiBone. }}$. This did not appear to adversely affect the estimates given the relatively small variance estimates for each.

\section{The Rumen}

Given intakes of 30,23 , and $22 \mathrm{~g} / \mathrm{d}$ of $\mathrm{Pp}, \mathrm{Po}$, and $\mathrm{Pi}$, respectively, the model predicted $8 \mathrm{~g} / \mathrm{d}$ of $\mathrm{Pp}$ flux to the small intestine and 57 and $64 \mathrm{~g} / \mathrm{d}$ of $\mathrm{Po}$ and $\mathrm{Pi}$, respectively (Figure 1). There was $4 \mathrm{~g} / \mathrm{d}$ of Pp converted to $\mathrm{Pi}$ and $19 \mathrm{~g} / \mathrm{d}$ conversion from $\mathrm{Pp}$ to $\mathrm{Po}$ in association with ruminal phytase activity. An additional $14 \mathrm{~g}$ of net $\mathrm{Po}$ was generated from $\mathrm{Pi}$ via microbial action, which was consistent with an expected synthesis rate of $12 \mathrm{~g} / \mathrm{d}$ based on average microbial P content (Durand and Kawashima, 1980) and the observed microbial flows (Schwab et al., 2006). Because Po was apparently in balance, it appears that net degradation of Po in the rumen did not occur although some turnover may have been occurring in association with microbial death. Positive net degradation of Po would have necessitated additional microbial synthesis to maintain the observed Po flow at the duodenum. Schwab et al. (2006) did not measure microbial $\mathrm{P}$ content preventing an assessment of the validity of this conclusion. 
Table 5. Correlation matrix for parameter estimates derived from the data of Schwab et al. (2006) and Knowlton et al. (2001) ${ }^{1}$

\begin{tabular}{lccccccc}
\hline & $K_{\text {PpRum,PiRum }}$ & $K_{\text {PiRum,PmRum }}$ & $K_{\text {PiBld,PiRum }}$ & $K_{\text {PoSI,PiSI }}$ & $K_{\text {PiBld,PiUrn }}$ & $K_{\text {Pibld,PiMlk }}$ & $K_{\text {PiSI,PiBld }}$ \\
\hline$K_{\text {PpRum,DegRum }}$ & 1 & & & & & & \\
$K_{\text {PiRum,PmRum }}$ & -0.16 & 1 & & & & & \\
$K_{\text {PiBld,PiRum }}$ & -0.10 & 0.42 & 1 & & & \\
$K_{\text {PoSI,PiSI }}$ & 0.12 & 0.54 & 0.30 & 1 & & \\
$K_{\text {PiBld,PiUrn }}$ & -0.03 & 0.019 & 0.11 & 0.006 & 1 & \\
$K_{\text {Pibld,PiMlk }}$ & -0.003 & 0.003 & 0.00 & 0.001 & 0.00 & 1 & \\
$K_{\text {PiSI,PiBld }}$ & 0.09 & 0.12 & -0.06 & 0.04 & -0.17 & 0.00 & 1 \\
$K_{\text {PiBld,PiBone }}$ & 0.24 & -0.03 & 0.38 & 0.05 & 0.19 & -0.14 & -0.58 \\
\hline
\end{tabular}

${ }^{1}$ Parameter abbreviations as given in Table 1.

Digestibility of $\mathrm{Pp}$ in the rumen was $74 \%$; however, flow of $\mathrm{Pt}$ at the duodenum was almost twice $\mathrm{Pt}$ intake due to extensive recycling from blood via saliva.

\section{SI and LI}

Approximately $52 \mathrm{~g} / \mathrm{d}$ of Po were converted to $\mathrm{Pi}$ in the SI, which, when combined with $64 \mathrm{~g} / \mathrm{d}$ of Pi influx from the rumen, resulted in $116 \mathrm{~g}$ of total $\mathrm{Pi}$ available in the SI. Of this, $82 \mathrm{~g} / \mathrm{d}$ were absorbed, leaving 34 $\mathrm{g} / \mathrm{d}$ to flow out of the small intestine. The digestion coefficients for $\mathrm{Po}$ and $\mathrm{Pi}$ in the small intestine were $89 \% \pm 0.01$ and $48 \% \pm 0.11$, respectively. However, these estimates are subject to the assumptions made for LI digestion. If these differences are representative of SI digestion, it would seem that the absorbable $\mathrm{P}$ supply in the SI is more subject to Pp content of the feed than it is Po. However, similar observations across a broad range of diets are needed to thoroughly test that conclusion.

Fecal output of Pp was observed to average $8 \mathrm{~g} / \mathrm{d}$. Flux of Pp into the LI was assumed to be the same as entry into the SI based on observations in monogastric species (Sandberg et al., 1987). This assumption was supported by the observation that fecal phytate output was equal to ruminal outflow. Fecal phytate outputs also indicate no degradation of this form of $\mathrm{P}$ in the LI. Thus, any phytate escaping ruminal degradation is resistant to further digestion and absorption in the lower tract and is excreted by the animal.

The majority of Po entering the SI was apparently converted to $\mathrm{Pi}$ because only $5 \mathrm{~g} / \mathrm{d}$ of $\mathrm{Po}$ appeared in feces. The observed digestion of Po represents a minimum as any microbial synthesis of Po in the LI requires additional digestion in the SI to maintain the observed fecal output. It was assumed that Po was not degraded in the LI and that $2 \mathrm{~g} / \mathrm{d}$ of Po was synthesized based on the expected rate of organic matter digestion in the LI. Parameter estimates were not very sensitive to either assumption. Degradation of 25\% of the Po flowing into the LI resulted in a $3.25 \%$ change in parameter estimate for Po digestion in the SI. A doubling of the rate of microbial synthesis of $\mathrm{Po}$ in the LI resulted in a 5\% change in the rate parameter for Po digestion in the SI and lesser changes for the remaining parameter estimates (Table 3). Further work is needed with animals that have ileal cannulae to uniquely define the cycling of $\mathrm{Pi}$ and $\mathrm{Po}$ in the lower tract.

Fecal output of $\mathrm{Pi}$ averaged $32 \mathrm{~g} / \mathrm{d}$ representing 2/3 $\mathrm{d}$ of fecal P. Based on the above conclusions, most of the $\mathrm{Pi}$ in feces is derived from $\mathrm{Pi}$ not absorbed from the SI or absorbed and returned to the digestive tract via secretions (Figure 1). Blood $\mathrm{P}$ was assumed to regulate $\mathrm{P}$ absorption rates and thus low $\mathrm{P}$ digestibility results from an excess of supply relative to postabsorptive use. An attempt was made to test that assumption by fitting the sensitivity exponent associated with $\mathrm{Pi}$ absorption ( $x_{P i S I, P i B l d}$; equation [21]), in which a value of zero negates the inhibitory effect of blood $\mathrm{P}$ on absorption and values greater than zero support the assumed feedback mechanism. However, the parameter was found to be highly correlated with the absorption coefficient, $K_{P i S I,-}$ $P i B l d$, and reliable values could not be derived given the available data. It is noteworthy that the greatest value for the log-likelihood function was achieved at a value of 1.22 for $x_{P i S I, P i B l d}$. Setting $x_{P i S I, P i B l d}$ to zero so that blood $\mathrm{P}$ had no effect on $\mathrm{P}$ absorption resulted in even greater slope bias in digestive flow predictions when the model was fitted to the data than when the value was set to 1 and the model fitted to the data. Although regulation of absorption appears to be the primary mechanism for regulating blood $\mathrm{P}$ concentrations, salivary reflux as suggested by Horst (1986) cannot be ruled out as a key component based on our work. Observations of duodenal $\mathrm{P}$ flow with varying total $\mathrm{P}$ supplies would allow differentiation of the site of regulation.

The digestibility of $\mathrm{Pt}$ in the intestine (SI + LI) was predicted to be $64 \pm 0.02 \%$, which is within the range observed for sheep subjected to varying P inputs (Scott et al., 1984).

\section{Blood and Bone P}

Of the $82 \mathrm{~g} / \mathrm{d}$ of $\mathrm{P}$ absorbed from the small intestine, $53 \mathrm{~g} / \mathrm{d}$ was recycled to the rumen, $1 \mathrm{~g} / \mathrm{d}$ was excreted 


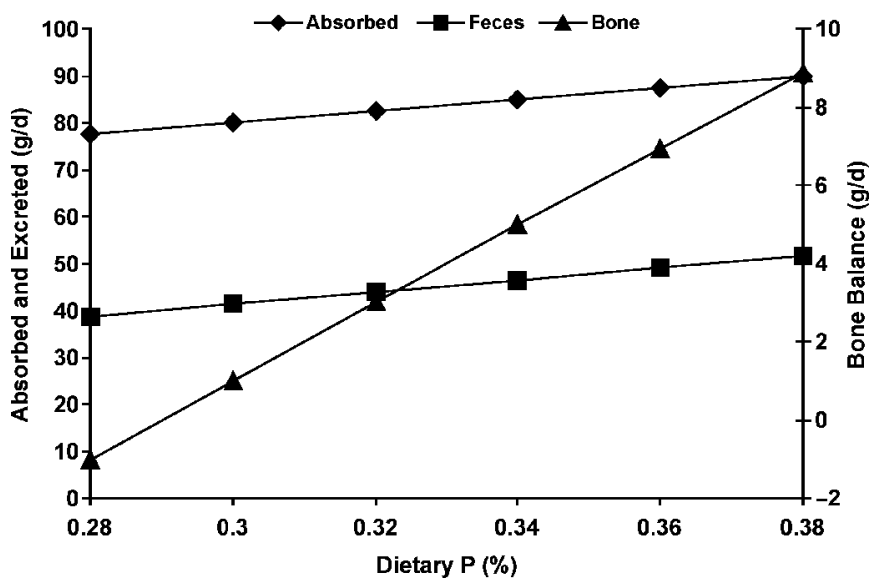

Figure 3. Absorption of phosphorus (P) from the intestine, $\mathrm{P}$ output in feces, and bone $\mathrm{P}$ balance in response to varied dietary $\mathrm{P}$. The ratio of phytate $\mathrm{P}$, organic $\mathrm{P}$ excluding phytate, and inorganic $\mathrm{P}$ were held constant as dietary $\mathrm{P}$ content was varied.

in urine, $25 \mathrm{~g} / \mathrm{d}$ was secreted in milk, and $4 \mathrm{~g} / \mathrm{d}$ was deposited in bone (Figure 1). Recycled $\mathrm{P}$ represented $41.4 \%$ of the total $\mathrm{P}$ input to the rumen, which is in close agreement to the $45 \%$ recycling reported by Kebreab and Vitti (2005).

Although net accretion of bone $\mathrm{P}$ was observed for these studies, such accretion obviously would not occur over the entire life-cycle of that animal. Presumably, the observed accretion represents restoration of bone $\mathrm{P}$ mass after a period of depletion; that is, early lactation. Additionally there is likely some maximum bone P mass that cannot be exceeded regardless of blood $\mathrm{P}$ concentrations. Such a possible limitation has not been included in the model, and thus it is possible that the model will predict excessive bone $\mathrm{P}$ mass over extended simulation periods with high dietary $\mathrm{P}$ inputs. Additional data related to such a potential mechanism is required to support inclusion and parameterization in the model.

As might be expected given such high rates of bone turnover, $\mathrm{P}$ balance was responsive to both dietary $\mathrm{P}$ (Figure 3) and phytase activity (Figure 4). Balance ranged from -1 to $9 \mathrm{~g} / \mathrm{d}$ when dietary $\mathrm{P}$ in the reference diet was varied from 0.28 to $0.38 \%$ of diet DM. Phosphorus balance was slightly less sensitive to phytase activity ranging from $+3.5 \mathrm{~g} / \mathrm{d}$ when phytase activity was increased to $160 \%$ of the derived value and $0 \mathrm{~g} / \mathrm{d}$ when phytase activity was reduced to $40 \%$ of the derived value. These ranges in balance were achieved with less than a 5\% range in blood $\mathrm{P}$ concentrations.

\section{Sensitivity Analysis}

Results of sensitivity analyses are presented in Figure 3 and Table 6. Absorption of Pi from the SI was

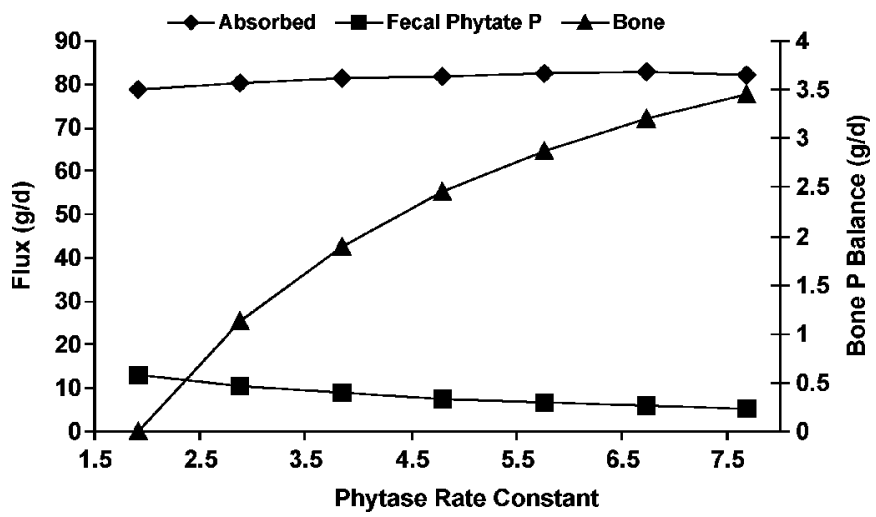

Figure 4. Absorption of phosphorus (P) from the intestine, excretion of phytate $\mathrm{P}$ in feces, and net bone $\mathrm{P}$ balance as phytase activity $\left(K_{P p R u m, P i R u m}\right)$ was altered from the derived value of $4.8 \mathrm{~d}^{-1}$.

relatively sensitive to dietary $\mathrm{P}$ concentrations. The majority of absorbed $\mathrm{P}$ was re-secreted into the digestive tract and eventually lost in feces as previously observed (Knowlton and Herbein, 2002). Although changes in bone $\mathrm{P}$ balance were not extremely responsive to a reasonable range of dietary $\mathrm{P}$ concentrations owing to the large amount of $\mathrm{P}$ cycling through blood into saliva, $\mathrm{P}$ balance did become negative at a dietary $\mathrm{P}$ content less than $0.30 \%$, which is slightly less than the requirements set by NRC (2001). Although gut absorption of dietary $\mathrm{P}$ continued to respond to reduced $\mathrm{P}$ availability by increasing $\mathrm{P}$ extraction, according to the model positive bone $\mathrm{P}$ balance could not be maintained. Although these observations are consistent with current $\mathrm{P}$ requirements, further work on $\mathrm{P}$ cycling in bone is required to define model parameters associated with deposition and resorption and additional observations are needed to define the sensitivity of the blood $\mathrm{P}$ feedback mechanism associated with $\mathrm{P}$ absorption. In particular, $\mathrm{P}$ cycling in bone may be more sensitive to blood $\mathrm{P}$ concentrations than reflected in the model due to the effects of vitamin $\mathrm{D}$ and parathyroid hormone (Goff, 2000). If that is the case, negative bone balance may occur at a greater dietary $\mathrm{P}$ concentration than suggested in this work.

Phosphorus absorption from the SI was not very sensitive to ruminal phytase activity (Figure 4). This was due in part to the blood regulation of transport activity that caused activity to respond reciprocally to Pi supply in the SI. Although reductions in absorption were small when compared with total flow, they were almost identical to reductions in bone $\mathrm{P}$ balance. Bone $\mathrm{P}$ balance was reduced from +3.5 to $0 \mathrm{~g} / \mathrm{d}$ when ruminal phytase activity ranged from $160 \%$ of the derived value to $40 \%$ of the derived value, underscoring the importance of phytase activity on $\mathrm{P}$ balance in the animal. Current 
Table 6. Sensitivity analysis after fitting to data of Schwab et al. (2006) and Knowlton et al. (2001) ${ }^{1}$

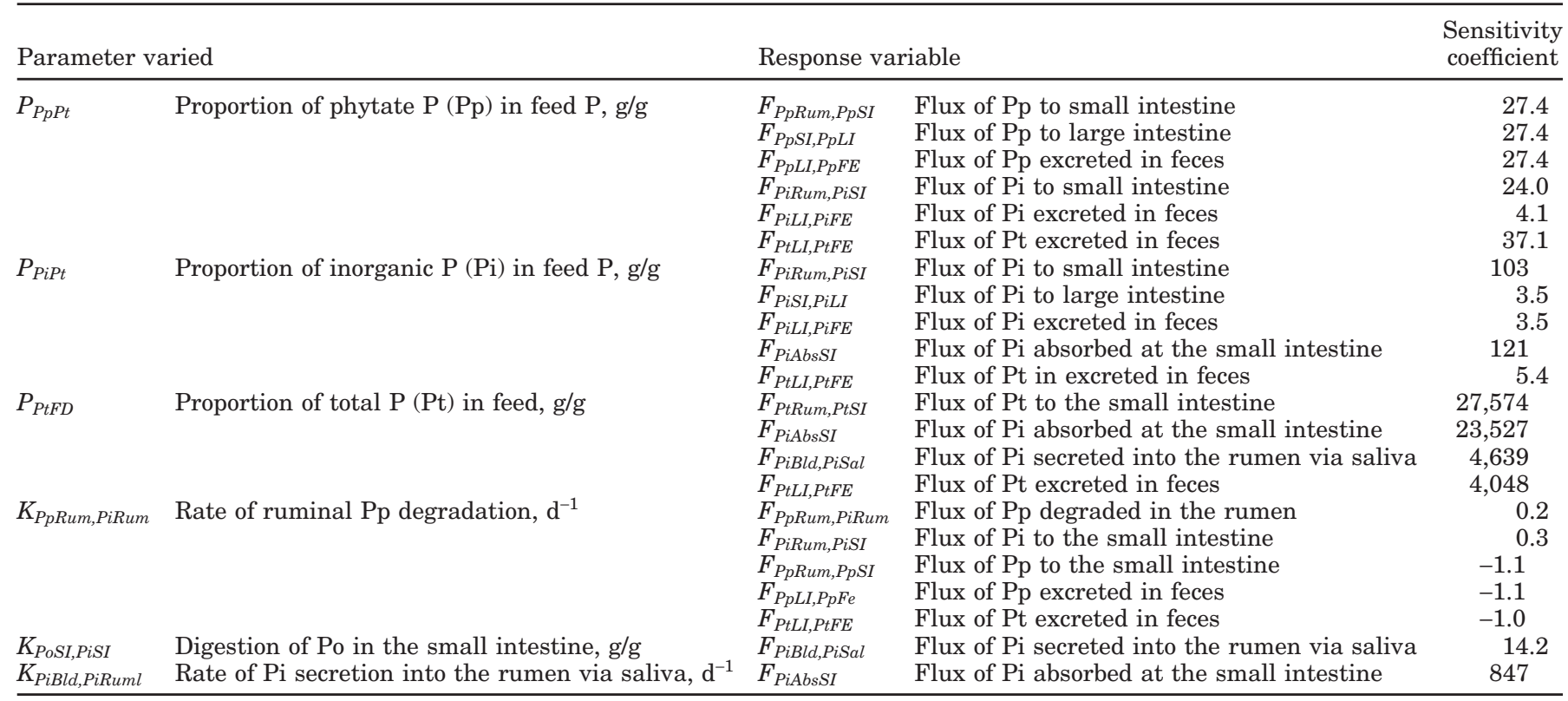

${ }^{1}$ Sensitivity coefficients are calculated according to equation [39] and represent the change in the response variable (g/d) resulting from a 1-unit change in the varied parameter.

information is not adequate to determine whether the range in phytase activity is consistent with the biological range, or perhaps is less than the biological range. In the absence of such information, greater safety margins must be included in requirement systems to compensate for the assumed variation in phytate availability.

Fluxes of $\mathrm{Pp}$ within the gut and output in feces were moderately sensitive to changes in composition of dietary P. Increasing the proportion of Pp in dietary $\mathrm{P}$ resulted in a 6 -fold greater fecal output of $\mathrm{Pt}$ as a comparable change in the proportion of $\mathrm{Pi}$ in dietary $\mathrm{P}$. Surprisingly, digestive $\mathrm{P}$ flux and absorption was not very sensitive to ruminal phytase activity. A doubling of phytase activity resulted in about a $3 \mathrm{~g} / \mathrm{d}$ improvement in absorption and a halving of activity resulted in about a $5 \mathrm{~g} / \mathrm{d}$ reduction in absorption (Figure 4). However, $\mathrm{P}$ balance was affected by these changes with a $3.5 \mathrm{~g} / \mathrm{d}$ range in $\mathrm{P}$ balance associated with halving and doubling phytase activity.

\section{CONCLUSIONS}

The data were adequate to derive parameters related to phytate degradation in the rumen and hindgut, microbial use of $\mathrm{P}$, intestinal digestion of nonphytate organic $\mathrm{P}$, absorption of inorganic $\mathrm{P}$, and recycling of blood $\mathrm{P}$ into the rumen via saliva. The derived model described the data with reasonable accuracy and precision, but some systematic bias was observed. The model predicted that changing total $\mathrm{P}$ concentration in the diet had a greater effect on total $\mathrm{P}$ excretion than changing any fraction of $\mathrm{P}$ in the diet. Total $\mathrm{P}$ excreted was not very sensitive to altering phytase activity, but it did affect $\mathrm{P}$ balance. Absorption appears to be an important site of regulation. Additional data are needed to derive parameters associated with regulation of $\mathrm{P}$ absorption and bone $\mathrm{P}$ turnover.

\section{ACKNOWLEDGMENTS}

This material is based upon work supported by the Cooperative State Research, Education and Extension Service, US Department of Agriculture, under Project No. NC-1009. Funding provided by the Virginia State Dairymen's Association is gratefully acknowledged. Funding for EK and JF was partly provided by the Canada Research Chairs Program. Any opinions, findings, conclusions, or recommendations expressed in this publication are those of the author(s) and do not necessarily reflect the view of the US Department of Agriculture.

\section{REFERENCES}

Bibby, J., and H. Toutenberg. 1977. Prediction and improved estimation in linear models. Wiley, Chichester, UK.

Bravo, D., D. Sauvant, C. Bogaert, and F. Meschy. 2003. II. Quantitative aspects of phosphorus absorption in ruminants. Reprod. Nutr. Dev. 43:271-284.

Breves, G., and H. Holler. 1987. Effects of dietary phosphorus depletion in sheep on dry matter and organic matter digestibility. J. Anim. Physiol. Anim. Nutr. (Berl.) 58:280-286. 
Callison, S. L., J. L. Firkins, M. L. Eastridge, and B. L. Hull. 2001. Site of nutrient digestion by dairy cows fed corn of different particle sizes or steam-rolled. J. Dairy Sci. 84:1458-1467.

Cassida, K. A., and M. R. Stokes. 1986. Eating and resting salivation in early lactation dairy cows. J. Dairy Sci. 69:1282-1292.

Clark, W. D., J. E. Wohlt, R. L. Gilbreath, and P. K. Zajac. 1986. Phytate phosphorus intake and disappearance in the gastrointestinal tract of high producing dairy cows. J. Dairy Sci. 69:31513155 .

Dias, R. S., E. Kebreab, D. M. S. S. Vitti, A. P. Roque, I. C. S. Bueno, and J. France. 2006. A revised model for studying phosphorus and calcium kinetics in growing sheep. J. Anim. Sci. 84:2787-2794.

Dou, Z., J. D. Ferguson, J. Fiorini, J. D. Toth, S. M. Alexander, L. E. Chase, C. M. Ryan, K. F. Knowlton, R. A. Kohn, A. B. Peterson, J. T. Sims, and Z. Wu. 2003. Phosphorus feeding levels and critical control points on dairy farms. J. Dairy Sci. 86:3787-3795.

Durand, M., and R. Kawashima. 1980. Influence of minerals in rumen microbial digestion. Pages 375-408 in Digestive Physiology and Metabolism in Ruminants. Y. Ruckebusch and P. Thivend, ed. AVI Publishing Company Inc., Westport, CT.

Eeckhout, W., and M. d. Paepe. 1994. Total phosphorus, phytatephosphorus and phytase activity in plant feedstuffs. Anim. Feed Sci. Technol. 47:19-29.

France, J., J. H. M. Thornley, R. L. Baldwin, and K. A. Crist. 1992. On solving stiff equations with reference to simulating ruminant metabolism. J. Theor. Biol. 156:525-539.

Georgievskii, V. I., B. N. Annenkov, and V. T. Samokhi. 1982. Mineral Nutrition of Animals: Studies in the Agricultural and Food Sciences. Butterworths, London, UK.

Godoy, S., C. Chicco, F. Meschy, and F. Requena. 2005. Phytic phosphorus and phytase activity of animal feed ingredients. Interciencia 30:24-28.

Goff, J. P. 2000. Pathophysiology of calcium and phosphorus disorders. Vet. Clin. North Am. Food Anim. Pract. 16:319-337.

Hibbs, J. W., and H. R. Conrad. 1983. The relationship of calcium and phosphorus intake and digestion and the effects of vitamin D feeding on the utilization of calcium and phosphorus by lactating dairy cows. Pages 1-23 in Research Bulletin 1150, The Ohio State University, Ohio Agric. Res. Dev. Center, Wooster, OH.

Horst, R. L. 1986. Regulation of calcium and phosphorus homeostasis in the dairy cow. J. Dairy Sci. 69:604-616.

Kebreab, E., and D. M. S. S. Vitti. 2005. Mineral metabolism. Pages 469-486 in Quantitative aspects of ruminant digestion and metabolism. J. Dijkstra, J. M. Forbes, and J. France, ed. CABI, Cambridge, UK.

Knowlton, K. F., and J. H. Herbein. 2002. Phosphorus partitioning during early lactation in dairy cows fed diets varying in phosphorus content. J. Dairy Sci. 85:1227-1236.

Knowlton, K. F., J. H. Herbein, M. A. Meister-Weisbarth, and W. A. Wark. 2001. Nitrogen and phosphorus partitioning in lactating Holstein cows fed different sources of dietary protein and phosphorus. J. Dairy Sci. 84:1210-1217.

Knowlton, K. F., M. S. Taylor, S. R. Hill, C. Cobb, and K. F. Wilson. 2007. Manure nutrient excretion by lactating cows fed exogenous phytase and cellulose. J. Dairy Sci. 90:4356-4360.

Komisarczuk, S., R. J. Merry, and A. B. McAllan. 1987. Effect of different levels of phosphorus on rumen microbial fermentation and synthesis determined using a continuous culture technique. Br. J. Nutr. 57:279-290.

Liao, S. F., A. K. Kies, W. C. Sauer, Y. C. Zhang, M. Cervantes, and J. M. He. 2005. Effect of phytase supplementation to a low- and a high-phytate diet for growing pigs on the digestibilities of crude protein, amino acids, and energy. J. Anim. Sci. 83:2130-2136.

Morse, D., H. H. Head, and C. J. Wilcox. 1992. Disappearance of phosphorus in phytate from concentrates in vitro and from rations fed to lactating dairy cows. J. Dairy Sci. 75:1979-1986.

NRC. 2001. Nutrient Requirements of Dairy Cattle. 7th rev. ed. National Academy Press, Washington, DC.

Sakamoto, K., I. Vucenik, and A. M. Shamsuddin. 1993. $\left[{ }^{3} \mathrm{H}\right] \mathrm{Phytic}$ acid (inositol hexaphosphate) is absorbed and distributed to various tissues in rats. J. Nutr. 123:713-720.

Sandberg, A. S., H. Andersson, N. G. Carlsson, and B. Sandstrom. 1987. Degradation products of bran phytate formed during digestion in the human small intestine: Effect of extrusion cooking on digestibility. J. Nutr. 117:2061-2065.

Schwab, E. C., C. G. Schwab, R. D. Shaver, C. L. Girard, D. E. Putnam, and N. L. Whitehouse. 2006. Dietary forage and nonfiber carbohydrate contents influence B-vitamin intake, duodenal flow, and apparent ruminal synthesis in lactating dairy cows. J. Dairy Sci. 89:174-187.

Scott, D., and W. Buchan. 1987. The effects of feeding either hay or grass diets on salivary phosphorus secretion, net intestinal phosphorus absorption and on the partition of phosphorus excretion between urine and faeces in the sheep. Q. J. Exp. Physiol. 72:331-338.

Scott, D., A. F. McLean, and W. Buchan. 1984. The effect of variation in phosphorus intake on net intestinal phosphorus absorption, salivary phosphorus secretion and pathway of excretion in sheep fed roughage diets. Q. J. Exp. Physiol. 69:439-452.

Swenson, M. J. 1993. Physiological properties and cellular and chemical constituents of blood. Pages 22-48 in Dukes' Physiology of Domestic Animals. M. J. Swenson and W. O. Reece, ed. Cornell University Press, Ithaca, NY.

Tomas, F. M. 1973. Parotid salivary secretion in sheep: Its measurement and influence on phosphorus in rumen fluid. Q. J. Exp. Physiol. 58:131-138.

Vandehaar, M. J., and N. St-Pierre. 2006. Major advances in nutrition: Relevance to the sustainability of the dairy industry. J. Dairy Sci. 89:1280-1291.

Vitti, D. M. S. S., E. Kebreab, J. B. Lopes, A. L. Abdalla, F. F. R. Carvalho, K. T. Resende, L. A. Crompton, and J. France. 2000. A kinetic model of phosphorus metabolism in growing goats. J. Anim. Sci. 78:2706-2712.

Witt, K. E., and F. N. Owens. 1983. Phosphorus: Ruminal availability and effects on digestion. J. Anim. Sci. 56:930-937.

Wu, Z., and L. D. Satter. 2000. Milk production and reproductive performance of dairy cows fed two concentrations of phosphorus for two years. J. Dairy Sci. 83:1052-1063.

Wu, Z., S. K. Tallam, V. A. Ishler, and D. D. Archibald. 2003. Utilization of phosphorus in lactating cows fed varying amounts of phosphorus and forage. J. Dairy Sci. 86:3300-3308.

Yang, T. H. 2006. Effects of diet on phosphorus digestion in dairy cattle. MS thesis. Virginia Polytechnic Institute and State University, Blacksburg. 